\title{
The endoplasmic reticulum, calcium signaling and junction turnover in Sertoli cells
}

\author{
Wayne Vogl ${ }^{1,2}$, Kevin Lyon², Arlo Adams ${ }^{1}$, Matthew Piva ${ }^{1}$ and Vanessa Nassour ${ }^{1}$ \\ ${ }^{1}$ Department of Cellular and Physiological Sciences, University of British Columbia, British Columbia, Canada and \\ ${ }^{2}$ Department of Obstetrics and Gynaecology, University of British Columbia, British Columbia, Canada
}

Correspondence should be addressed to W Vogl; Email:vogl@mail.ubc.ca

\begin{abstract}
The endoplasmic reticulum (ER) forms a continuous network throughout morphologically differentiated Sertoli cells. It is an integral component of intercellular adhesion junctions in this cell type, as well as forming membrane contact sites with the plasma membrane and intracellular organelles. One of the major functions of the ER in cells generally is maintaining calcium homeostasis and generating calcium signals. In this review, we discuss what is currently known about the overall pattern of distribution of the ER in Sertoli cells and the location of calcium regulatory machinery in the various subdomains of the organelle. Current data are consistent with the hypothesis that calcium signaling by the ER of Sertoli cells may play a significant role in events related to junction remodeling that occur in the seminiferous epithelium during spermatogenesis.

Reproduction (2018) 155 R93-R104
\end{abstract}

\section{Introduction}

Calcium signaling is a significant regulator of cell functions, and the endoplasmic reticulum (ER) plays a prominent role in the process (Burgoyne et al. 2015). Membrane contact sites between the ER and the organelles, and between the ER and the plasma membrane, are now well established as general features of eukaryotic cells (Gallo et al. 2016, Phillips \& Voeltz 2016). At these locations, the two adjacent membranes are separated by a gap of less than $30 \mathrm{~nm}$ (Gallo et al. 2016) and the sites are known to function in calcium exchange, as well as in lipid transfer (Gallo et al. 2016, Phillips \& Voeltz 2016). They also are locations where regulatory complexes are assembled and intracellular signaling occurs (Prinz 2014). In Sertoli cells, the distribution and relationships of the ER, the position of membrane contact sites and the location of calcium regulatory machinery indicate that ER-mediated calcium signaling may be of major significance during junction turnover related to spermatocyte translocation and sperm release in the seminiferous epithelium.

In cells generally, free calcium levels in the cytosol are much lower than that in extracellular fluid, and these levels are maintained by transporters in the plasma membrane and in the membranes of intracellular organelles that actively pump calcium out of the cytosol (Bootman 2012). Both local and more global changes and oscillations in cytosolic calcium levels, resulting from the activation of channels in the plasma membrane and/ or intracellular membranes, are used by cells to activate effectors that drive a multitude of activities including cell proliferation, exocytosis, secretion, migration, differentiation, gene transcription and contraction (Bootman et al. 2001, Berridge 2006, Bootman 2012). In sperm cells, changes in calcium levels are responsible for mediating events that occur during capacitation and the acrosome reaction (Breitbart 2002a,b, Lucchesi et al. 2016). Membrane contacts in cells are sites where calcium inflow through the plasma membrane can be coupled to calcium transfer into and out of organelles, and where calcium exchange between organelles can occur (Prinz 2014, Phillips \& Voeltz 2016).

In Sertoli cells, much work has been carried out to identify ion channels and pumps in the plasma membrane (Gorczynska \& Handelsman 1991, D'Agostino et al. 1992, Gorczynska et al. 1994, Rossato et al. 1996, Lalevee et al. 1997, Taranta et al. 1997, Lalevee \& Joffre 1999, Ko et al. 2003, GorczynskaFjalling 2004, Feng et al. 2006, Lai et al. 2008, Oliveira et al. 2009, Rato et al. 2010, Zanatta et al. 2011, Lucas et al. 2012). Most of this work has been carried out in primary cultures and in the context of determining how the cells regulate and produce seminiferous tubule fluid, maintain $\mathrm{pH}$ and initiate signaling cascades. Much less work has been carried out to localize ion channels and pumps in morphologically differentiated Sertoli cells in vivo and in the context of junction turnover, although a large number of other regulators and signaling pathways are known to impact the junctions (Cheng \& Mruk 2015). One ion pump that does appear specifically concentrated in the plasma membrane of Sertoli cells 
at apical and basal sites of intercellular attachment is $\mathrm{Na}+/ \mathrm{K}+$ ATPase (Byers \& Graham 1990). In addition, calcium ATPase has been localized to the Sertoli cell plasma membrane in the seminiferous epithelium (Feng et al. 2006).

In the testis, seminiferous tubule fluid is isosmotic with blood (Rato et al. 2010), but the two are very different in composition. One notable difference is that seminiferous tubule fluid has much higher levels of potassium than plasma (Tuck et al. 1970, Clulow \& Jones 2004). Although seminiferous tubule fluid has lower levels of calcium than blood (Jenkins et al. 1980, Clulow \& Jones 2004), it is still in the $\mathrm{mM}$ range and is much higher than cytosolic nM levels measured in cultured Sertoli cells (Gorczynska \& Handelsman 1991, D'Agostino et al. 1992, Rossato et al. 1996).

Morphologically differentiated Sertoli cells are generally columnar in shape and form the architectural
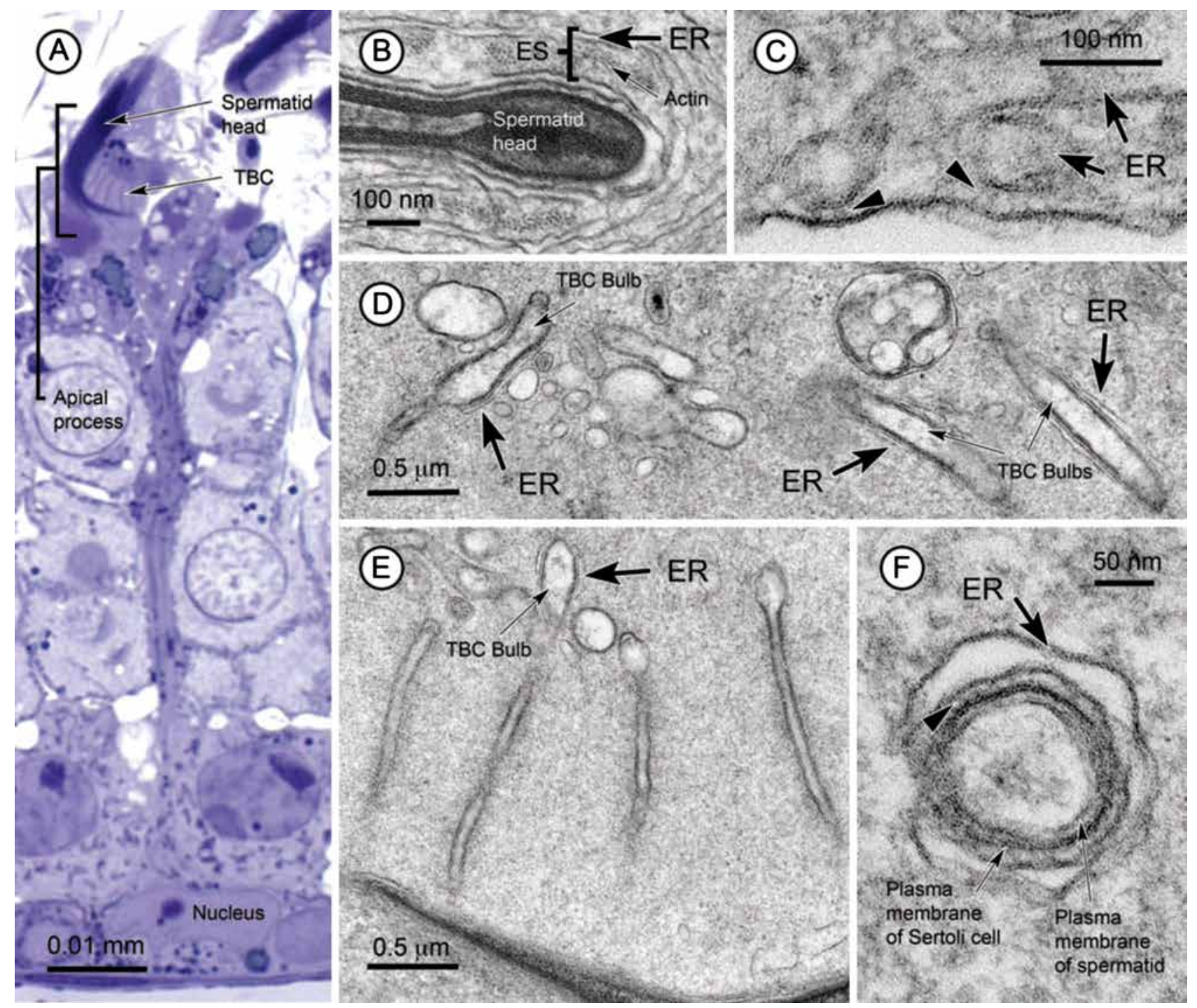

Figure 1 ER associations and membrane contacts in rat Sertoli cells. (A) Shown here is a Sertoli cell and related spermatogenic cells at Stage VII in a $0.7-\mu \mathrm{m}$ plastic section of seminiferous epithelium stained with toluidine blue. The Sertoli cell extends from base to apex of the epithelium. The nucleus is at the base of the cell and an apical process that surrounds a late spermatid is present at the luminal surface. Numerous TBCs are visible extending into the apical process from the concave face of the spermatid head. (B) Electron micrograph of an ES attached to part of a spermatid head. At these adhesion junctions, a layer of actin filaments separates the ER from the plasma membrane. (C) ER cisternae around the periphery of apical processes form close contacts with the Sertoli cell plasma membrane. Filamentous connections between the two membranes are seen within the gap (arrowheads). (D and E) Shown here are a number of TBCs that project into apical processes. Flattened cisternae of endoplasmic reticulum form close contacts with the bulbs of TBC. (F) Cross section of a TBC bulb. The plasma membranes of the Sertoli cell and spermatid are indicated. A flattened cistern of ER encapsulates the bulb forming close contact. Numerous linkages (arrowhead) are visible in the gap between the ER and the Sertoli cell plasma membrane. 
units of the mature seminiferous epithelium (Fig. 1A). They extend from the base to the apex of the epithelium, and the spermatogenic cells at different stages of development occur between and are attached to the Sertoli cells. As the spermatogenic cells differentiate, they move from the base to the apex of the epithelium where the head of each developing sperm cell becomes encapsulated and suspended at the luminal boundary of the seminiferous tubule by a projection of the Sertoli cell termed an 'apical process' (Fig. 1A). When these spermatogenic cells (spermatids) are morphologically mature, they are released as a spermatozoan from the apical processes and enter the duct system of the male reproductive tract.

The ER is a prominent element of the Sertoli cell and forms a structural component of intercellular junctions that attach Sertoli cells to each other and to spermatogenic cells in this system (Fawcett 1975). In addition, the ER forms membrane contacts at various locations in the cell, including at endocytic structures termed tubulobulbar complexes (TBCs) that function in junction internalization or disassembly (Russell et al. 1988, Guttman et al. 2004). This specific pattern of ER distribution in Sertoli cells (Lyon et al. 2017), together with the localization of calcium sensing and regulatory machinery in this organelle itself and at membrane contact sites, indicates that calcium may play important roles during junction remodeling.

In this review, we summarize what is known about the distribution of the ER in morphologically differentiated Sertoli cells in the seminiferous epithelium, with an emphasis on calcium regulation and a possible role in intercellular junction turnover.

\section{ER at junctions}

Cisternae of ER are a consistent feature of actin-related adhesion junctions known as ectoplasmic specializations (ESs). In fact, a cistern of ER together with an associated layer of actin filaments and the related region of the plasma membrane form a tripartite structural unit that characterizes these unique cell-specific junctions in morphologically differentiated Sertoli cells. At these sites, the actin filaments are bundled into para-crystalline arrays that form a layer separating the ER from the plasma membrane by a substantial gap (Fig. 1B) reported to be in the order of $50-100 \mathrm{~nm}$ depending on the study and species (Dym \& Fawcett 1970, Russell 1977b, Franke et al. 1978, Furuya et al. 1978, Lyon et al. 2017).

ESs occur both at basal and at apical locations in the epithelium. At basal sites, they form part of a junction complex that also includes tight and gap junctions, and where they are intercalated with intermediate filamentrelated desmosomes or 'desmosome-like' junctions. Tight junctions within this complex contribute to the 'blood-testis barrier' (Dym \& Fawcett 1970). Turnover of these junction complexes is necessary for the next generation of spermatogenic cells to move from basal to adluminal compartments during each cycle of the epithelium. During this process, junctions disassemble above the translocating cells, while simultaneously new junctions assemble below (Russell 1977a, Smith \& Braun 2012). At apical sites, ESs form the major class of attachment to the haploid spermatogenic cells or spermatids. When spermatids are mature, these attachments are disassembled and the cells are released from the epithelium. At the same time, new junctions

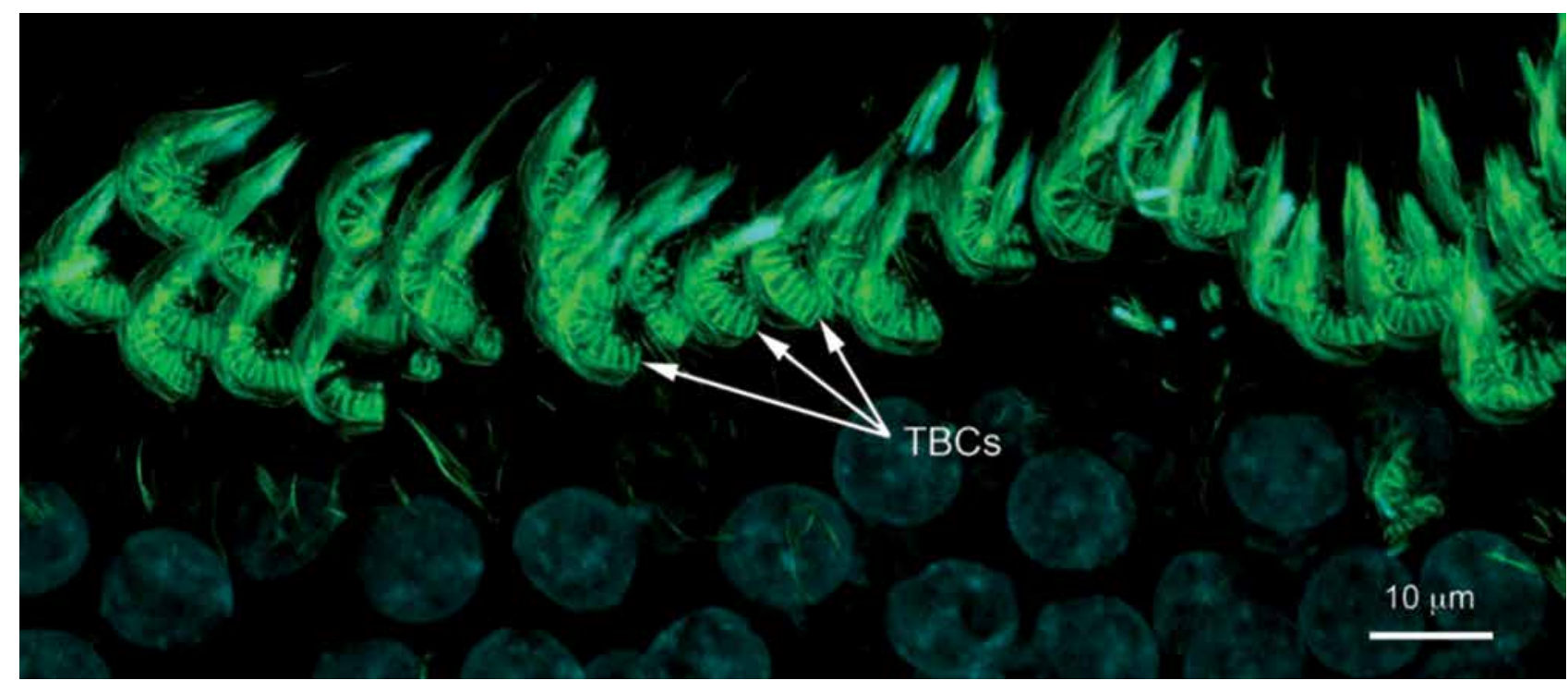

Figure $2 \mathrm{~A}$ confocal maximum projection image of a z-stack collected from a section of rat seminiferous epithelium illustrating the large number of TBCs that develop at the apex of the epithelium at Stage VII. Clusters of TBCs project into apical Sertoli cell processes that envelop the heads of late spermatids. The TBCs are labeled with fluorescent phallotoxin which stains actin filaments. Nuclei are labeled with DAPI. 
assemble with elongating early spermatids lower in the epithelium firmly anchoring these cells to the tissue.

Based on the presence of $E R$ at the adhesion junctions, a role for calcium signaling in the regulation and turnover of ESs has long been suspected, but direct evidence for its involvement at the sites continues to be lacking. Means and coworkers speculated that the ER of these junctions may function to store calcium and that release of the
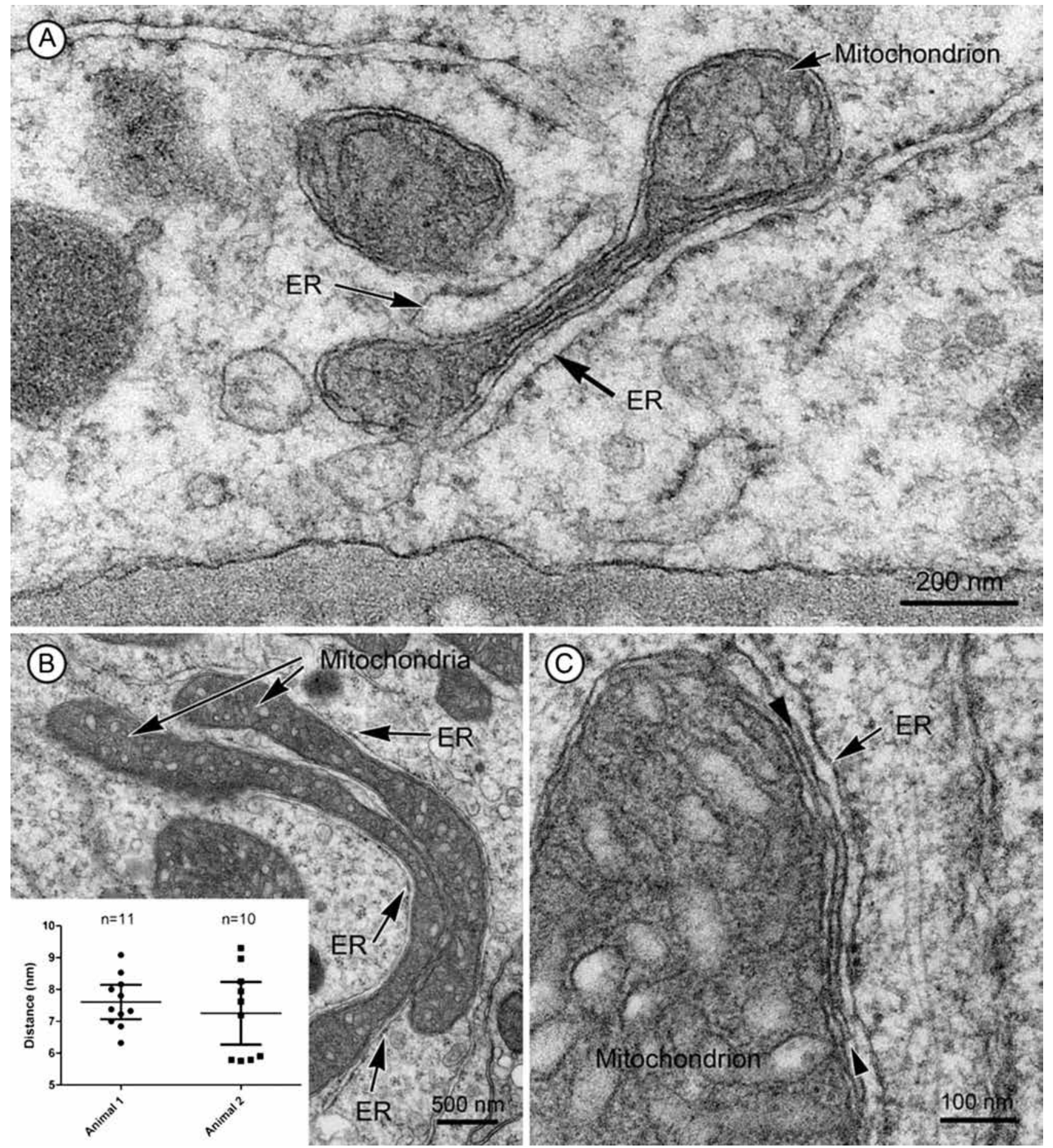

Figure 3 Membrane contact sites at mitochondria. (A) Close contacts between the mitochondria and the ER are most noticeable in basal regions of Sertoli cells. Notice that the ER is rough, but ribosomes are absent from the ER membrane facing the close contact. (B) Close contacts are extensive with the mitochondria and in some cases appear to almost encapsulate the organelles. The inset shows the measured distance between the ER and the mitochondria in two different animals. (C) Shown here is a magnified view of a close contact between the ER and a mitochondrion. Linkages are visible in the gap (arrowheads) between the two organelles. 
cation may generate contraction of the associated actin layer (Means et al. 1980). Using chemical precipitation techniques combined with electron microscopy, others have presented evidence that calcium is sequestered in the ER at the junction sites (Franchi \& Camatini 1985b). In addition, it has been reported that calcium chelation with EGTA results in an alteration of the arrangement of junction components within the plasma membrane when analyzed by freeze fracture, and that treatment with

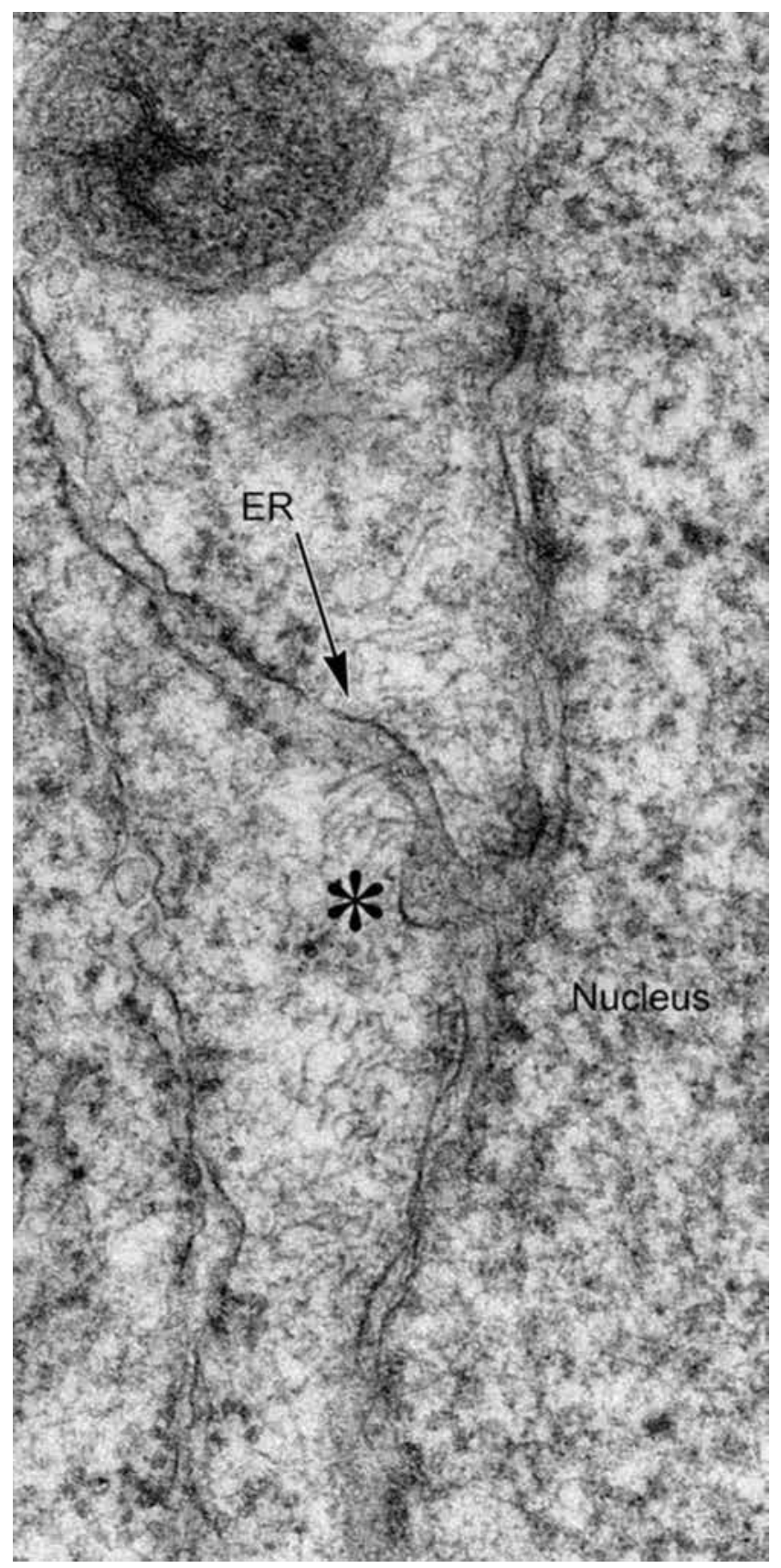

Figure 4 At the base of the cell, the ER is continuous with the nuclear envelope at numerous locations, one of which is illustrated here (asterisk). trifluoroperazine (an inhibitor of the calcium-binding protein calmodulin) results both in disorganization of the actin filament bundles in ESs and separation of the ER away from the junctions (Franchi \& Camatini 1985a). The absence of myosin $2(\mathrm{MYH} 2)$ and the lack of contraction when exposed to appropriate buffer systems (Vogl \& Soucy 1985) support the conclusion that any changes in local calcium levels that may occur at ESs likely induce structural changes in the actin bundles that do not involve contraction as earlier thought.

One way in which this structural effect on the actin bundles of ESs has been suggested to be mediated by calcium is through a mechanism involving phosphoinositide-specific phospolipase C (PLCG1) and the inositol 1,4,5-trisphosphate $\left(\mathrm{IP}_{3}\right)$ pathway (Guttman et al. 2002). In this pathway, PLCG1 cleaves phosphatidylinositol 4,5-bisphosphate $\left(\mathrm{PIP}_{2}\right)$ in the membrane releasing inositol 1,4,5-trisphosphate $\left(\mathrm{IP}_{3}\right)$ which then binds to the $I_{3}$ receptor $\left(I P_{3} R\right.$; ITPR) in the ER resulting in the release of stored calcium (Bootman 2012) which then affects the activity of calciumdependent actin-binding proteins. However, and unlike predicted, $I P_{3} R$ does not appear concentrated at the sites (Lyon et al. 2017), although $\mathrm{PIP}_{2}$ and PLC $\gamma$ are both present at ESs (Guttman et al. 2002).

It is possible that microdomains of low calcium in the actin layer between the plasma membrane and the ER are created by the activity of 'sarco/endoplasmic reticulum $\mathrm{Ca}^{2+}$-ATPase 2' (SERCA2; ATP2A2) pumps in the ER of ESs and by calcium ATPase in the related plasma membrane. These microdomains of low calcium might act to stabilize the actin bundles in ESs. At specific locations and at specific times, calcium channels within the plasma membrane, or perhaps as yet unidentified channels in the ER, may become activated to elevate the level of calcium and initiate filament disassembly. One possibility is that $\mathrm{IP}_{3}$ may directly activate T-type calcium channels in the plasma membrane (Lai et al. 2008) to focally elevate calcium levels at specific sites in the actin layer. Another is that focal areas of membrane depolarization could activate voltagedependent calcium channels in the plasma membrane. The presence of plastin 3 (PLS3), an actin-bundling protein that is directly regulated by calcium, in ESs may be significant in relation to changes in calcium levels (Li et al. 2015). Elevations in calcium within the actin layer may lead to unbundling of the actin filaments and their eventual disassembly which, in turn, is somehow linked to the generation of TBCs and construction of their dendritic actin networks. The presence of annexin A2 (ANXA2), another calcium-dependent phospholipid and actin-binding protein at ESs, and at TBCs, may play a role in the conversion from ES-type actin organization to that of TBCs. Knockdown of annexin results in both impaired TBCs and incomplete sperm release, as well as a disruption of basal junction complexes (Chojnacka et al. 2017). In addition to a direct effect on 
calcium-dependent proteins located in ESs, oscillations in calcium levels at the sites also may have indirect effects on the cytoskeleton via alternative pathways, as is known to occur in other systems (Sun et al. 2014).

\section{ER/plasma membrane contacts}

There are at least two locations in Sertoli cells that are sites of contact between the ER and the plasma membrane, and calcium regulatory machinery has been localized to both. One of these sites is in association with the margins of apical Sertoli cell processes that each surrounds the head of a late spermatid and its related cluster of TBCs, and the other is in association with the bulbs of TBCs themselves.

At the margins of apical processes, cisternae of ER occur adjacent to the plasma membrane. In rat Sertoli cells at Stage VII of spermatogenesis, concentric sheets of fenestrated ER occur at the periphery of each apical process (Clermont et al. 1980). The outermost cistern
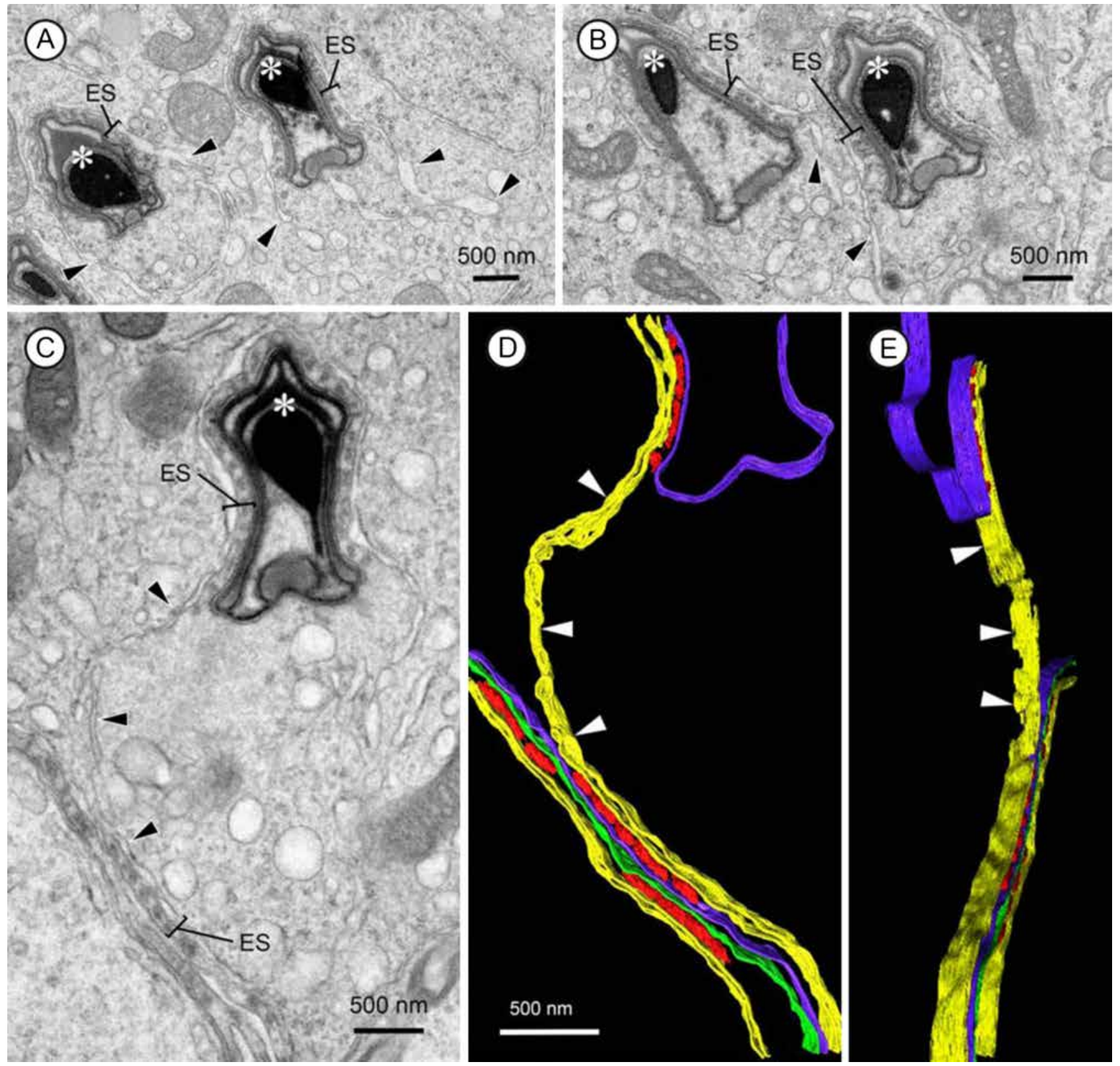

Figure 5 The ER of ESs associated with elongate spermatids deep in Sertoli cell crypts in Stage $V$ of the seminiferous epithelium is continuous with the general ER network in the cells. (A and B) The ER of ESs associated with elongate spermatid heads (asterisks) extends away from ES and into the Sertoli cell cytoplasm (arrowheads). (C) Shown in this electron micrograph of a thick section of the epithelium is a cistern of ER (arrowheads) that is continuous between an ES associated with an elongate spermatid head (asterisk) and an ES associated with a basal junction. (D and E) Tomograms of the ER (yellow) and Sertoli cell plasma membranes (green and blue) in (C). Actin filaments in the ESs are shown in red. 
of ER is swollen and forms close contacts with the plasma membrane (Fig. 1C) (Lyon et al. 2017). At these sites, elements of the ER are separated from the plasma membrane by gaps of only around $13-14 \mathrm{~nm}$, and fine filamentous connections often occur spanning the gaps. Immunofluorescence data indicate that 'stromal interaction molecule-1' (STIM1) and the Orai 1 (ORAI1) channel are co-distributed at the sites (Lyon et al. 2017), an observation which is consistent with the hypothesis that store-operated calcium entry occurs here. In cells generally, STIM1 in the ER membrane senses low calcium levels within the ER (Liou et al. 2005, Roos et al. 2005) and interacts with ORAI1 in the plasma membrane (Muik et al. 2008, Park et al. 2009). This interaction results in the clustering of ORAI1 to form channels that allow calcium entry into the cell (Prakriya et al. 2006). This influx of calcium into the cytosol can then be sequestered into ER stores by pumps such as
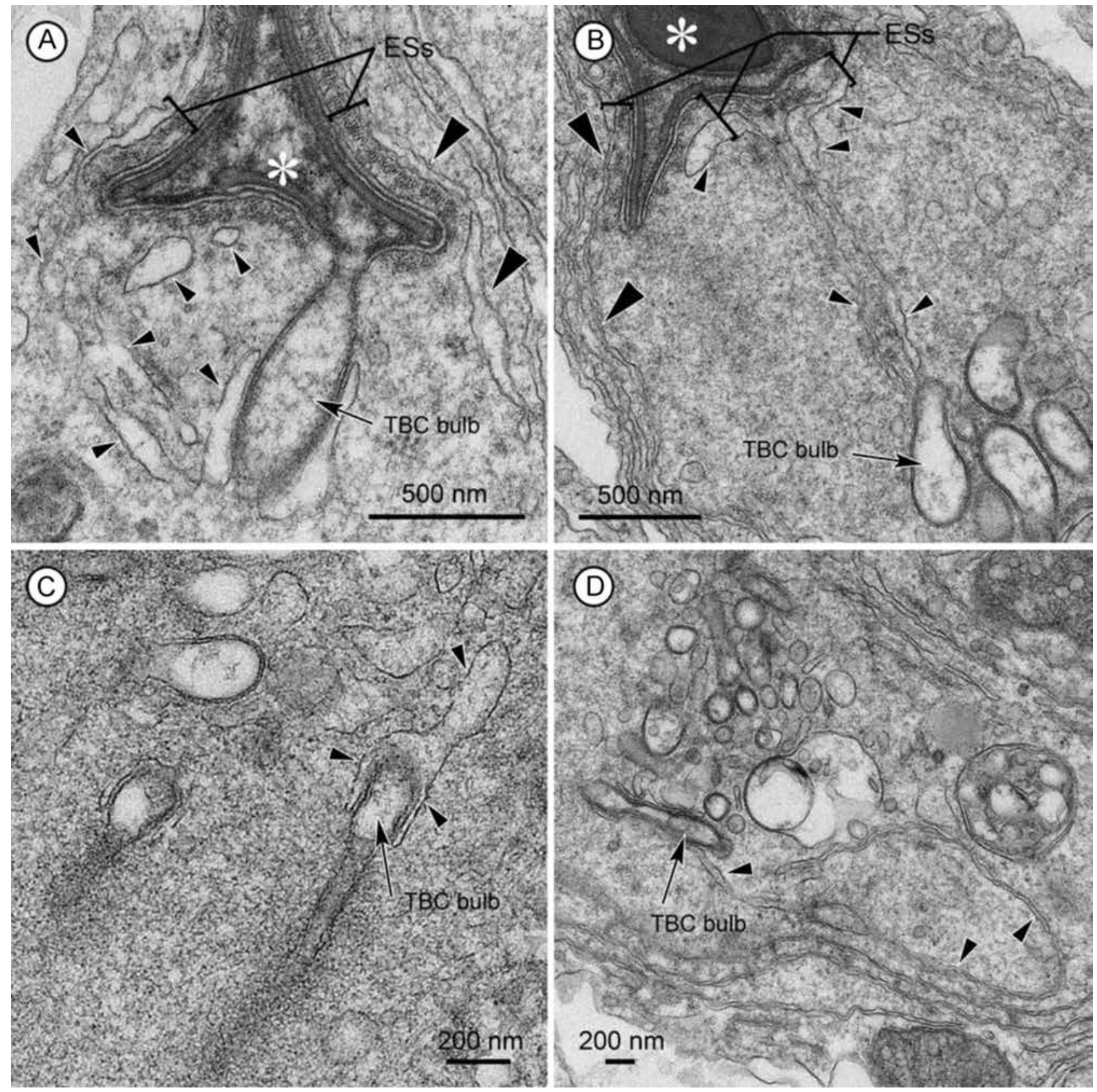

Figure 6 The ER forms a continuous network in apical processes of Sertoli cells. (A and B) The ER of ESs is continuous with the ER at the periphery of apical processes (large arrowheads) and with the ER encapsulating the bulbs of TBCs (small arrowheads) (spermatid heads are indicated by the asterisks). (C and D) The ER that forms close contacts with TBC bulbs extends away from the bulbs and is continuous with the ER elsewhere in apical processes (arrowheads). 
SERCA2 (ATP2A2) which has been shown to be widely distributed in the ER throughout Sertoli cells (Lyon et al. 2017).
AtTBCs, cisternae of ER associate directly with regions of the structures that ultimately are 'endocytosed'. TBCs are clathrin-dependent subcellular structures that

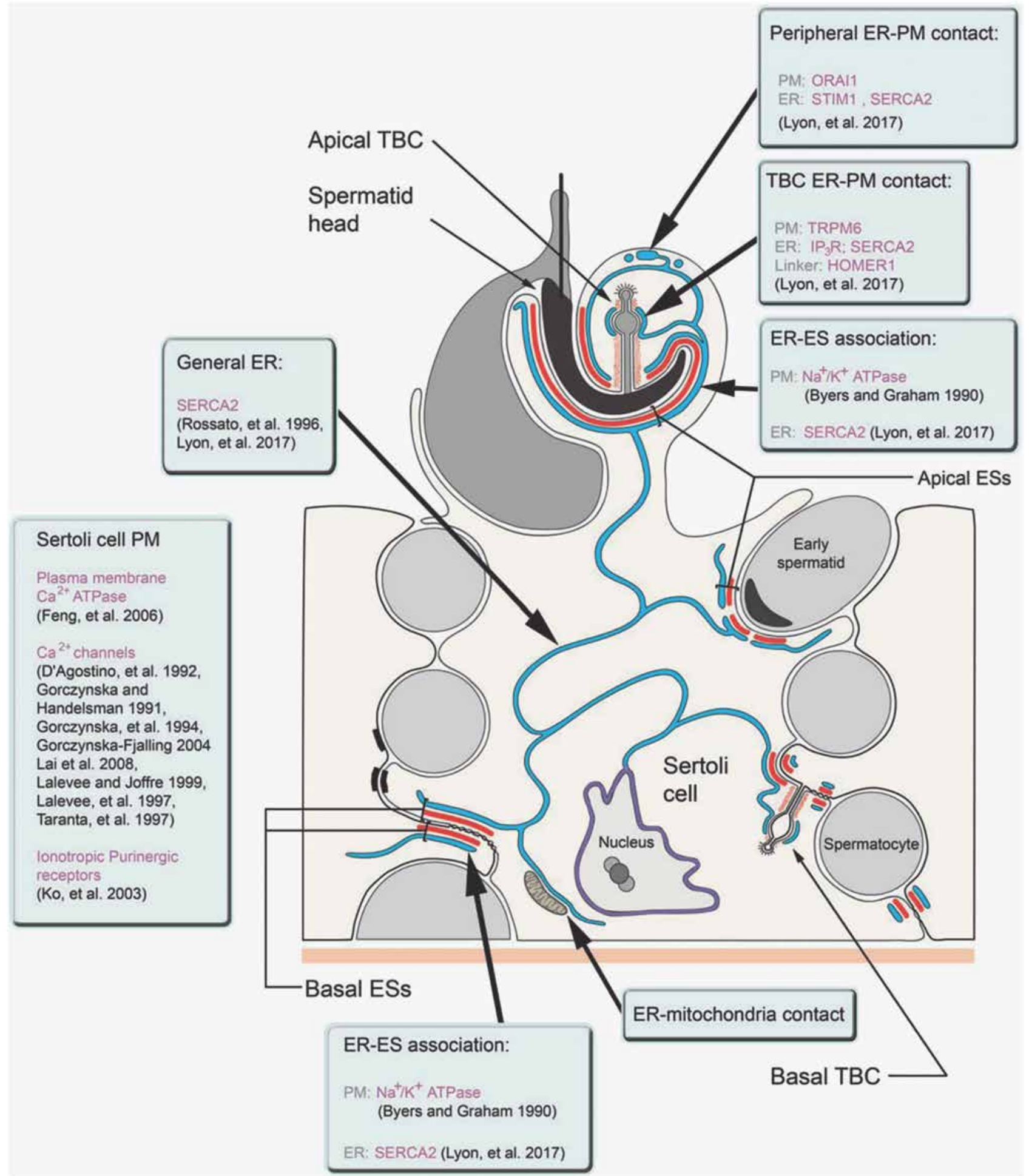

Figure 7 Illustrated here is the general pattern of ER in rat Sertoli cells. The ER is in blue and actin filaments at ESs and at TBCs are in red. The positions of ER close contacts and associations with ESs are indicated. Components that have been identified at the various sites are indicated in the boxes. ER, endoplasmic reticulum; ES, ectoplasmic specialization; PM, plasma membrane. 
internalize intercellular junctions (Vogl et al. 2014) and that are unique to Sertoli cells. They develop at apical junctions between Sertoli cells and late spermatids and at basal junction complexes between neighboring Sertoli cells (Russell \& Clermont 1976). Classically, each complex is described as having a long proximal tubule, a swollen or 'bulb' region, a small distal tubule and a terminal coated pit (Russell \& Clermont 1976) (Fig. 1D and $E$ ). In each apical process of the rat seminiferous epithelium, a cluster of as many as 24 complexes develop in association with the concave face of the hook-shaped spermatid head (Fig. 1A). One of a number of unique features of TBCs is that they consist of the plasma membranes of the two attached cells - in other words, their core is formed by two plasma membranes which remain attached. The tubular region of the double membrane core is cuffed by a dendritic actin network (Vaid et al. 2007, Young et al. 2009) that in turn has an outer shell containing plectin (PLEC) and spectrin (SPTAN) (de Asis et al. 2013). As TBCs form, they resemble clathrin-coated pits with extremely long necks, reaching as long as $1-2 \mu \mathrm{m}$ in most eutherian mammals (Russell \& Malone 1980). When fully formed, and near the end of each complex, the tubular region swells into a 'bulb', which then expands proximally and eventually undergoes scission to be internalized by the Sertoli cell (Lyon et al. 2015). The bulb does not have a cuff of actin filaments, but is encapsulated by a cistern of ER. The ER and Sertoli cell plasma membrane are separated by a gap of around $12 \mathrm{~nm}$ (Lyon et al. 2017) which is well within the range of an ER-plasma membrane contact or junction (Fig. 1F).

New data from immunolocalization studies of apically located TBCs indicate that $I_{3} R$ is concentrated in the ER at the sites (Lyon et al. 2017). Also present is at least one 'transient receptor potential channel' (TRPM6) in the plasma membrane at the sites. Transient receptor potential (TRP) channels are part of a large family of proteins that are variably permeable to many ions including calcium (Clapham et al. 2001). Many TRP channels have been localized to the heads of spermatozoa where they are predicted to be involved in the acrosomal reaction as well as other yet-to-beidentified functions (Darszon et al. 2012). Others have used RT-PCR to detect mRNA of the various TRP channels in rat testis and then localized the upregulated TRPs to spermatogenic cells generally using immunohistochemistry (Li et al. 2010). However, TRPM6 is the only TRP channel to have been immunolocalized directly to a specific compartment of Sertoli cells (i.e. TBC bulbs). TRPM6 belongs to the melastatin-related subfamily (TRPM), which contains channels that are highly permeable to divalent cations such as calcium and magnesium. The various TRPM channels may be activated, for example, by mechanisms such as binding by calcium and lipid compounds or by membrane voltage changes (Kraft \& Harteneck 2005).
Along with $\mathrm{IP}_{3} \mathrm{R}$ (ITPR) and TRPM6, the Homer 1 (HOMER1) scaffolding protein is also present at TBC-ER contacts. Homer1 is known to be a crucial scaffolding protein between $I P_{3} R$ (ITPR) and other TRP receptors (Yuan et al. 2003). Homer1 therefore may link TRP channels such as TRPM6 to IP $R$ in the ER at these sites. The exact function of membrane contact sites at the bulbs of TBCs has yet to be clarified; however, ER membrane contact sites are known to form with elements of the endosomal pathway in cells generally where they have been implicated both in calcium crosstalk between the organelles, and in lipid transport (Burgoyne et al. 2015, Phillips \& Voeltz 2016). At TBC bulbs, any calcium fluxes that occur could affect the cytoskeletal networks in tubular regions adjacent to the bulb, or impact the bulb itself which is destined to be internalized by the Sertoli cell and become a large 'endosome'.

The internalization of intercellular junctions by TBCs is unique to the seminiferous epithelium and close contacts between the ER and the bulbs of the structures are a characteristic feature. Collectively, the large numbers of TBCs that form at the apex of the epithelium preceding sperm release are truly remarkable (Fig. 2).

\section{ER/mitochondrion contacts}

One area that has received little attention in Sertoli cells is the relationship between the ER and the mitochondria. In cells generally, mitochondria are known to store significant amounts of calcium and to participate in maintaining calcium homeostasis in the cytosol (Alonso et al. 2006). In fact, mitochondria are thought to buffer increased calcium levels generated from the plasma membrane and other organelles, and to modulate calcium microdomains in the cytoplasm (Alonso et al. 2006). Membrane contacts between the ER and the mitochondria are sites of calcium exchange and lipid transfer between the two organelles (Prinz 2014, Giacomello \& Pellegrini 2016). Contact sites also are involved with mitochondrial division (Friedman et al. 2011), and with initiating apoptosis (Prudent \& McBride 2017). In addition, changes in calcium levels within mitochondria can modulate energy production by the organelles, which is particularly important during the early phases of ER stress (Bravo et al. 2011).

In Sertoli cells, extensive regions of close contact between these two organelles consistently are observed, particularly near the base of the cells (Fig. 3A). As at other ER membrane contact sites, the gap between the two opposing membranes is narrow, approximately $7-8 \mathrm{~nm}$ (Fig. 3B), and filamentous connections span the gap (Fig. 3C). Interestingly, the ER at the base of the cells tends to be mainly rough ER. As cisternae approach the mitochondria and form contact sites, ribosomes become absent from the membrane facing the junction, whereas they often still occur on the outer or cytoplasmic membrane of the ER. Currently, nothing is known about 
these ER-mitochondria contact sites in Sertoli cells and it remains to be determined if and how they are related to calcium homeostasis in the cells during spermatogenesis and junction turnover.

\section{The ER in Sertoli cells is a continuous network}

Based mainly on ultrastructural studies presented below and elsewhere (Clermont et al. 1980), and data from immunofluorescence studies, particularly of SERCA2 (ATP2A2) pumps (Lyon et al. 2017), the ER in Sertoli cells forms a network throughout the Sertoli cell. The ER is continuous with the nuclear envelope at the base of the cell (Fig. 4), and extends peripherally to become a component of ESs where it is separated from the plasma membrane by a layer of hexagonally packed actin filaments (Fig. 5A and B). Interestingly, the ER of those ESs associated with elongate spermatids at Stage $\mathrm{V}$ in the rat can be seen to be continuous with those at basal ESs in favorable sections (Fig. 5C) particularly when viewed in tomograms (Fig. 5D and E). In apical processes, the ER of ESs associated with late spermatid heads is continuous with that around the periphery of the processes and with that related to the bulbs of TBCs (Clermont et al. 1980) (Fig. 6A and B). The ER of the bulbs is continuous between bulbs and with cisternae around the periphery of the apical processes (Fig. 6C and D). The ER forms close contacts or 'junctions' with the bulbs of TBCs, with the plasma membrane elsewhere at the periphery of the cell, and with mitochondria. The morphology of the system and the distribution of specific protein components indicate that although the ER is continuous throughout the cell, it has a number of distinct structural, and probably functional, domains (Fig. 7). Because intercellular junctions and other features of the Sertoli cell are cyclically remodeled during spermatogenesis, these domains must, by necessity, be very fluid and dynamic.

We suspect that calcium may be loaded into the ER at peripheral contacts with the plasma membrane, as well as at ER throughout the cell, and that oscillations and/or transfer of the cation may occur at ESs and TBCs. At junctions, any changes in calcium levels that may occur likely impact the cytoskeleton. The function of any calcium fluxes at the bulbs of TBCs is unclear. ER-mitochondria contacts in Sertoli cells have not been studied, and their changes during spermatogenesis and their functions in this system are also unknown.

\section{Conclusion and future work}

The presence of cisternae of ER as structural components of intercellular junctions in Sertoli cells, the close contact of cisternae with structures known to be involved with junction internalization in the epithelium and the presence of calcium regulatory machinery at both these locations, as well as more generally in the ER, all point to the probable importance of calcium signaling to junction turnover in this system.

In the future, it will be necessary to accurately catalog all pumps and channels at the sites and to determine if transient changes in calcium levels actually do occur in relation to specific subdomains of the ER in the Sertoli cell. It then will be essential to relate any fluctuations in calcium levels to corresponding morphological changes. Adapting fluorescent protein calcium sensor technology to the seminiferous epithelium to track local transient calcium changes during live cell imaging with two-photon excitation microscopy will be important to determine if calcium fluxes occur. Coupling this approach with electron microscopic and immunofluorescence studies to correlate these fluxes with morphological changes will be important to determine the function of the fluxes. Knockdown of the calcium regulatory machinery in the testis and evaluating the phenotypes will be another productive approach to determining function. In addition to studies related to calcium exchange, it would be interesting to determine if lipid transfer also occurs at ER membrane contact sites, particularly those at TBCs. Ultimately, these sorts of studies will clarify the role of the ER in Sertoli cell-mediated events that occur during spermatogenesis, in particular the role of the ER in junction remodeling as it relates to sperm release and the translocation of spermatocytes through the 'bloodtestis' barrier.

\section{Declaration of interest}

None of the authors have any financial or other potential conflict of interest that could be perceived as prejudicing the impartiality of this review.

\section{Funding}

This work was supported by the Natural Sciences and Engineering Research Council (NSERC) of Canada (grant number RGPIN 155397-13).

\section{References}

Alonso MT, Villalobos C, Chamero P, Alvarez J \& Garcia-Sancho J 2006 Calcium microdomains in mitochondria and nucleus. Cell Calcium $\mathbf{4 0}$ 513-525. (https://doi.org/10.1016/j.ceca.2006.08.013)

Berridge MJ 2006 Calcium microdomains: organization and function. Cell Calcium 40 405-412. (https://doi.org/10.1016/j.ceca.2006.09.002)

Bootman MD 2012 Calcium signaling. Cold Spring Harbor Perspectives in Biology 4 a011171. (https://doi.org/10.1101/cshperspect.a011171)

Bootman MD, Lipp P \& Berridge MJ 2001 The organisation and functions of local $\mathrm{Ca}(2+)$ signals. Journal of Cell Science $1142213-2222$.

Bravo R, Vicencio JM, Parra V, Troncoso R, Munoz JP, Bui M, Quiroga C, Rodriguez AE, Verdejo HE, Ferreira J et al. 2011 Increased ERmitochondrial coupling promotes mitochondrial respiration and bioenergetics during early phases of ER stress. Journal of Cell Science 124 2143-2152. (https://doi.org/10.1242/jcs.080762)

Breitbart H 2002a Intracellular calcium regulation in sperm capacitation and acrosomal reaction. Molecular and Cellular Endocrinology 187 139-144. (https://doi.org/10.1016/S0303-7207(01)00704-3) 
Breitbart H 2002b Role and regulation of intracellular calcium in acrosomal exocytosis. Journal of Reproductive Immunology 53 151-159. (https://doi.org/10.1016/S0165-0378(01)00085-7)

Burgoyne T, Patel S \& Eden ER 2015 Calcium signaling at ER membrane contact sites. Biochimica et Biophysica Acta 1853 2012-2017. (https://doi.org/10.1016/j.bbamcr.2015.01.022)

Byers S \& Graham R 1990 Distribution of sodium-potassium ATPase in the rat testis and epididymis. American Journal of Anatomy 188 31-43. (https://doi.org/10.1002/aja.1001880105)

Cheng CY \& Mruk DD 2015 Biochemistry of Sertoli cell/germ cell junctions, germ cell transport, and spermiation i the seminiferous epithelium. In Serrtoli Cell Biology, pp 333-383. Ed MD Griswold Amsterdam: Elsevier.

Chojnacka K, Bilinska B \& Mruk DD 2017 Annexin A2 is critical for bloodtestis barrier integrity and spermatid disengagement in the mammalian testis. Biochimica et Biophysica Acta 1864 527-545. (https://doi. org/10.1016/j.bbamcr.2016.12.012)

Clapham DE, Runnels LW \& Strubing C 2001 The TRP ion channel family. Nature Reviews Neuroscience 2 387-396. (https://doi. org/10.1038/35077544)

Clermont Y, McCoshen J \& Hermo L 1980 Evolution of the endoplasmic reticulum in the Sertoli cell cytoplasm encapsulating the heads of late spermatids in the rat. Anatomical Record 196 83-99. (https://doi. org/10.1002/ar.1091960109)

Clulow J \& Jones RC 2004 Composition of luminal fluid secreted by the seminiferous tubules and after reabsorption by the extratesticular ducts of the Japanese quail, Coturnix coturnix japonica. Biology of Reproduction 71 1508-1516. (https://doi.org/10.1095/biolreprod.104.031401)

D'Agostino A, Mene P \& Stefanini M 1992 Voltage-gated calcium channels in rat Sertoli cells. Biology of Reproduction 46 414-418.

Darszon A, Sanchez-Cardenas C, Orta G, Sanchez-Tusie AA, Beltran C, Lopez-Gonzalez I, Granados-Gonzalez G \& Trevino CL 2012 Are TRP channels involved in sperm development and function? Cell and Tissue Research 349 749-764. (https://doi.org/10.1007/s00441-012-1397-5)

de Asis MA, Pires M \& Lyon K 2013 A network of spectrin and plectin surrounds the actin cuffs of apical tubulobulbar complexes in the rat. Spermatogenesis 3 e25733. (https://doi.org/10.4161/spmg.25733)

Dym M \& Fawcett DW 1970 The blood-testis barrier in the rat and the physiological compartmentation of the seminiferous epithelium. Biology of Reproduction 3 308-326. (https://doi.org/10.1093/ biolreprod/3.3.308)

Fawcett DW 1975 Ultrastructure and function of the Sertoli cell. In Handbook of Physiology, pp 21-55. Ed RO Greep. Baltimore: Williams \& Wilkins.

Feng HL, Hershlag A, Han YB \& Zheng LJ 2006 Localizations of intracellular calcium and Ca2+-ATPase in hamster spermatogenic cells and spermatozoa. Microscopy Research and Technique 69 618-623. (https://doi.org/10.1002/jemt.20329)

Franchi E \& Camatini M 1985a Evidence that a Ca2+ chelator and a calmodulin blocker interfere with the structure of inter-Sertoli junctions. Tissue and Cell 17 13-25. (https://doi.org/10.1016/00408166(85)90012-6)

Franchi E \& Camatini M 1985b Morphological evidence for calcium stores at Sertoli-Sertoli and Sertoli-spermatid interrelations. Cell Biology International Reports 9 441-446. (https://doi.org/10.1016/03091651(85)90152-3)

Franke WW, Grund C, Fink A, Weber K, Jockusch BM, Zentgraf H \& Osborn M 1978 Location of actin in the microfilament bundles associated with the junctional specializations between Sertoli cells and spermatids. Biology of the Cell 31 7-14.

Friedman JR, Lackner LL, West M, DiBenedetto JR, Nunnari J \& Voeltz GK 2011 ER tubules mark sites of mitochondrial division. Science 334 358-362. (https://doi.org/10.1126/science.1207385)

Furuya S, Kumamoto Y \& Sugiyama S 1978 Fine structure and development of Sertoli junctions in human testis. Archives of Andrology 1 211-219. (https://doi.org/10.3109/01485017808988339)

Gallo A, Vannier C \& Galli T 2016 Endoplasmic reticulum-plasma membrane associations: structures and functions. Annual Review of Cell and Developmental Biology 32 279-301. (https://doi.org/10.1146/ annurev-cellbio-111315-125024)

Giacomello M \& Pellegrini L 2016 The coming of age of the mitochondriaER contact: a matter of thickness. Cell Death and Differentiation 23 1417-1427. (https://doi.org/10.1038/cdd.2016.52)
Gorczynska E \& Handelsman DJ 1991 The role of calcium in folliclestimulating hormone signal transduction in Sertoli cells. Journal of Biological Chemistry 266 23739-23744.

Gorczynska E, Spaliviero J \& Handelsman DJ 1994 The relationship between 3',5'-cyclic adenosine monophosphate and calcium in mediating follicle-stimulating hormone signal transduction in Sertoli cells. Endocrinology 134 293-300. (https://doi.org/10.1210/ endo.134.1.8275946)

Gorczynska-Fjalling E 2004 The role of calcium in signal transduction processes in Sertoli cells. Reproductive Biology 4 219-241.

Guttman JA, Janmey P \& Vogl AW 2002 Gelsolin - evidence for a role in turnover of junction-related actin filaments in Sertoli cells. Journal of Cell Science 115 499-505.

Guttman JA, Takai Y \& Vogl AW 2004 Evidence that tubulobulbar complexes in the seminiferous epithelium are involved with internalization of adhesion junctions. Biology of Reproduction 71 548-559. (https://doi. org/10.1095/biolreprod.104.028803)

Jenkins AD, Lechene CP \& Howards SS 1980 Concentrations of seven elements in the intraluminal fluids of the rat seminiferous tubules, rate testis, and epididymis. Biology of Reproduction 23 981-987. (https://doi. org/10.1095/biolreprod23.5.981)

Ko WH, Au CL \& Yip CY 2003 Multiple purinergic receptors lead to intracellular calcium increases in cultured rat Sertoli cells. Life Science 72 1519-1535. (https://doi.org/10.1016/S0024-3205(02)02410-4)

Kraft R \& Harteneck C 2005 The mammalian melastatin-related transient receptor potential cation channels: an overview. Pflügers Archiv 451 204-211. (https://doi.org/10.1007/s00424-005-1428-0)

Lai TH, Lin YF, Wu FC \& Tsai YH 2008 Follicle-stimulating hormoneinduced Galphah/phospholipase C-delta1 signaling mediating a noncapacitative $\mathrm{Ca} 2+$ influx through T-type $\mathrm{Ca} 2+$ channels in rat sertoli cells. Endocrinology 149 1031-1037. (https://doi.org/10.1210/en.20071244)

Lalevee N \& Joffre M 1999 Inhibition by cAMP of calcium-activated chloride currents in cultured Sertoli cells from immature testis. Journal of Membrane Biology 169 167-174. (https://doi.org/10.1007/ s002329900528)

Lalevee N, Pluciennik F \& Joffre M 1997 Voltage-dependent calcium current with properties of T-type current in Sertoli cells from immature rat testis in primary cultures. Biology of Reproduction 56 680-687. (https://doi.org/10.1095/biolreprod56.3.680)

Li S, Wang X, Ye H, Gao W, Pu X \& Yang Z 2010 Distribution profiles of transient receptor potential melastatin- and vanilloid-related channels in rat spermatogenic cells and sperm. Molecular Biology Reports 37 1287-1293. (https://doi.org/10.1007/s11033-009-9503-9)

Li N, Mruk DD, Wong CK, Lee WM, Han D \& Cheng CY 2015 Actinbundling protein plastin 3 is a regulator of ectoplasmic specialization dynamics during spermatogenesis in the rat testis. FASEB Journal 29 3788-3805. (https://doi.org/10.1096/fj.14-267997)

Liou J, Kim ML, Heo WD, Jones JT, Myers JW, Ferrell JE \& Meyer T 2005 STIM is a Ca2+ sensor essential for $\mathrm{Ca} 2+$-store-depletion-triggered Ca2+ influx. Current Biology 15 1235-1241. (https://doi.org/10.1016/j. cub.2005.05.055)

Lucas TF, Amaral LS, Porto CS \& Quintas LE $2012 \mathrm{Na}+\mathrm{K}+$-ATPase alpha1 isoform mediates ouabain-induced expression of cyclin D1 and proliferation of rat sertoli cells. Reproduction 144 737-745. (https://doi. org/10.1530/REP-12-0232)

Lucchesi O, Ruete MC, Bustos MA, Quevedo MF \& Tomes CN 2016 The signaling module cAMP/Epac/Rap1/PLCepsilon/IP3 mobilizes acrosomal calcium during sperm exocytosis. Biochimica et Biophysica Acta 1863 544-561. (https://doi.org/10.1016/j.bbamcr.2015.12.007)

Lyon KR, Bosseboeuf E \& Vogl AW 2015 An alternative model of tubulobulbar complex internalization during junction remodeling in the seminiferous epithelium of the rat testis. Biology of Reproduction 9312. (https://doi.org/10.1095/biolreprod.115.128942)

Lyon K, Adams A, Piva M, Asghari P, Moore ED \& Vogl AW 2017 Ca2+ signaling machinery is present at intercellular junctions and structures associated with junction turnover in rat Sertoli cells. Biology of Reproduction 96 1288-1302. (https://doi.org/10.1093/biolre/iox042)

Means AR, Dedman JR, Tash JS, Tindall DJ, $M$ van Sickle \& Welsh MJ 1980 Regulation of the testis Sertoli cell by follicle stimulating hormone. Annual Review of Physiology 42 59-70. (https://doi.org/10.1146/ annurev.ph.42.030180.000423) 
Muik M, Frischauf I, Derler I, Fahrner M, Bergsmann J, Eder P, Schindl R, Hesch C, Polzinger B, Fritsch R et al. 2008 Dynamic coupling of the putative coiled-coil domain of ORAI1 with STIM1 mediates ORAI1 channel activation. Journal of Biological Chemistry 283 8014-8022. (https://doi.org/10.1074/jbc.M708898200)

Oliveira PF, Sousa M, Barros A, Moura T \& Rebelo da Costa A 2009 Intracellular $\mathrm{pH}$ regulation in human Sertoli cells: role of membrane transporters. Reproduction 137 353-359. (https://doi.org/10.1530/REP08-0363)

Park CY, Hoover PJ, Mullins FM, Bachhawat P, Covington ED, Raunser S, Walz T, Garcia KC, Dolmetsch RE \& Lewis RS 2009 STIM1 clusters and activates CRAC channels via direct binding of a cytosolic domain to Orai1. Cell 136 876-890. (https://doi.org/10.1016/j.cell.2009.02.014)

Phillips MJ \& Voeltz GK 2016 Structure and function of ER membrane contact sites with other organelles. Nature Reviews Molecular Cell Biology 17 69-82. (https://doi.org/10.1038/nrm.2015.8)

Prakriya M, Feske S, Gwack Y, Srikanth S, Rao A \& Hogan PG 2006 Orai1 is an essential pore subunit of the CRAC channel. Nature 443 230-233. (https://doi.org/10.1038/nature05122)

Prinz WA 2014 Bridging the gap: membrane contact sites in signaling, metabolism, and organelle dynamics. Journal of Cell Biology 205 759-769. (https://doi.org/10.1083/jcb.201401126)

Prudent J \& McBride HM 2017 The mitochondria-endoplasmic reticulum contact sites: a signalling platform for cell death. Current Opinion in Cell Biology 47 52-63. (https://doi.org/10.1016/j.ceb.2017.03.007)

Rato L, Socorro S, Cavaco JE \& Oliveira PF 2010 Tubular fluid secretion in the seminiferous epithelium: ion transporters and aquaporins in Sertoli cells. Journal of Membrane Biology 236 215-224. (https://doi. org/10.1007/s00232-010-9294-x)

Roos J, DiGregorio PJ, Yeromin AV, Ohlsen K, Lioudyno M, Zhang S, Safrina O, Kozak JA, Wagner SL, Cahalan MD et al. 2005 STIM1, an essential and conserved component of store-operated Ca2+ channel function. Journal of Cell Biology 169 435-445. (https://doi.org/10.1083/ jcb.200502019)

Rossato M, Bordon P, Di Virgilio F \& Foresta C 1996 Capacitative calcium entry in rat Sertoli cells. Journal of Endocrinological Investigation 19 516-523. (https://doi.org/10.1007/BF03349010)

Russell L 1977a Movement of spermatocytes from the basal to the adluminal compartment of the rat testis. American Journal of Anatomy 148 313-328. (https://doi.org/10.1002/aja.1001480303)

Russell L 1977b Observations on rat Sertoli ectoplasmic ('junctional') specializations in their association with germ cells of the rat testis. Tissue and Cell 9 475-498. (https://doi.org/10.1016/0040-8166(77)90007-6)

Russell L \& Clermont Y 1976 Anchoring device between Sertoli cells and late spermatids in rat seminiferous tubules. Anatomical Record $\mathbf{1 8 5}$ 259-278. (https://doi.org/10.1002/ar.1091850302)

Russell LD \& Malone JP 1980 A study of Sertoli-spermatid tubulobulbar complexes in selected mammals. Tissue and Cell 12 263-285. (https://doi.org/10.1016/0040-8166(80)90005-1)

Russell LD, Goh JC, Rashed RM \& Vogl AW 1988 The consequences of actin disruption at Sertoli ectoplasmic specialization sites facing spermatids after in vivo exposure of rat testis to cytochalasin D. Biology of Reproduction 39 105-118. (https://doi.org/10.1095/biolreprod39.1.105) Smith BE \& Braun RE 2012 Germ cell migration across Sertoli cell tight junctions. Science 338 798-802. (https://doi.org/10.1126/ science.1219969)

Sun J, Lu F, He H, Shen J, Messina J, Mathew R, Wang D, Sarnaik AA, Chang WC, Kim M et al. 2014 STIM1- and Orai1-mediated $\mathrm{Ca}(2+)$ oscillation orchestrates invadopodium formation and melanoma invasion. Journal of Cell Biology 207 535-548. (https://doi.org/10.1083/ jcb.201407082)

Taranta A, Morena AR, Barbacci E \& A D'Agostino 1997 omega-Conotoxinsensitive $\mathrm{Ca} 2+$ voltage-gated channels modulate protein secretion in cultured rat Sertoli cells. Molecular and Cellular Endocrinology 126 117-123. (https://doi.org/10.1016/S0303-7207(96)03973-1)

Tuck RR, Setchell BP, Waites GM \& Young JA 1970 The composition of fluid collected by micropuncture and catheterization from the seminiferous tubules and rete testis of rats. Pflügers Archiv 318 225-243. (https://doi. org/10.1007/BF00593663)

Vaid KS, Guttman JA, Babyak N, Deng W, McNiven MA, Mochizuki N, Finlay BB \& Vogl AW 2007 The role of dynamin 3 in the testis. Journal of Cellular Physiology 210 644-654. (https://doi.org/10.1002/jcp.20855)

Vogl AW \& Soucy LJ 1985 Arrangement and possible function of actin filament bundles in ectoplasmic specializations of ground squirrel Sertoli cells. Journal of Cell Biology 100 814-825. (https://doi.org/10.1083/ jcb.100.3.814)

Vogl AW, Du M, Wang XY \& Young JS 2014 Novel clathrin/actinbased endocytic machinery associated with junction turnover in the seminiferous epithelium. Seminars in Cell and Developmental Biology 30 55-64. (https://doi.org/10.1016/j.semcdb.2013.11.002)

Young JS, Guttman JA, Vaid KS, Shahinian H \& Vogl AW 2009 Cortactin (CTTN), N-WASP (WASL), and clathrin (CLTC) are present at podosomelike tubulobulbar complexes in the rat testis. Biology of Reproduction $\mathbf{8 0}$ 153-161. (https://doi.org/10.1095/biolreprod.108.070615)

Yuan, JP, Kiselyov K, Shin DM, Chen J, Shcheynikov N, Kang SH, Dehoff MH, Schwarz MK, Seeburg PH, Muallem S et al. 2003 Homer binds TRPC family channels and is required for gating of TRPC1 by IP3 receptors. Cell 114 777-789. (https://doi.org/10.1016/S00928674(03)00716-5)

Zanatta L, Zamoner A, Goncalves R, Zanatta AP, Bouraima-Lelong H, Carreau S \& Silva FR 2011 1alpha,25-Dihydroxyvitamin D(3) signaling pathways on calcium uptake in 30-day-old rat Sertoli cells. Biochemistry 50 10284-10292. (https://doi.org/10.1021/bi201113n)

Received 9 May 2017

First decision 10 July 2017

Revised manuscript received 12 September 2017

Accepted 23 October 2017 